\title{
Hemorrhagic cerebral infarction in carbon monoxide poisoning: a
}

\section{case report}

\author{
Mostafa El Khashab ${ }^{1}$ and Farideh Nejat*2
}

Address: ${ }^{1}$ Department of Neurosurgery, Hackensack University Medical Center, New Jersey, USA and ${ }^{2}$ Department of Neurosurgery, Children's Hospital Medical Center, Tehran University of Medical Sciences, Tehran, Iran

Email: Mostafa El Khashab - mostkash@yahoo.com; Farideh Nejat* - nejat@sina.tums.ac.ir

* Corresponding author

Published: 29 January 2009

Cases Journal 2009, 2:96 doi:10.1186/1757-1626-2-96

This article is available from: $h t t p: / / w w w . c a s e s j o u r n a l . c o m / c o n t e n t / 2 / 1 / 96$

(C) 2009 El Khashab and Nejat; licensee BioMed Central Ltd.

This is an Open Access article distributed under the terms of the Creative Commons Attribution License (http://creativecommons.org/licenses/by/2.0), which permits unrestricted use, distribution, and reproduction in any medium, provided the original work is properly cited.

\begin{abstract}
Introduction: Almost every known central neurological syndrome has been reported as a complication of carbon monoxide poisoning. Hemorrhagic infarct has rarely been considered as an early manifestation of carbon monoxide poisoning. A case of cerebral hemorrhagic infarction is presented. Typical findings, neuropathology and the role of vascular injury are described.
\end{abstract}

Case presentation: The symptoms and clinical course of acute poisoning with carbon monoxide in a 7-year-old boy are described. To evaluate the possible causes, a brain computed tomography (CT) was performed that showed thick clot in the left medial temporal and parasellar area, left sylvian fissure(acute intravascular thrombus) accompanied by left diffuse frontotemporal hypodensity and midline shift. Four-vessel digital subtraction angiography two weeks after intoxication was not indicative of any vascular lesion.

Conclusion: Hemorrhagic infarction is a rare presentation of carbon monoxide poisoning. When found in a child, in addition to conservative treatment to reduce the neurocognitive squeal, other probable causes should be ruled out.

\section{Introduction}

Carbon monoxide $(\mathrm{CO})$ poisoning is a leading cause of poisoning death. Infants and children may be at a higher risk of toxicity because their exposure is increased by high minute ventilation volume and high metabolic rate. Commonly the cerebral lesions occur in the basal ganglia, and central gray and white matters. Pathologic changes can include necrosis of globus pallidus, spongy change in the cerebral cortex, and necrosis or demyelination in the cerebral or cerebellar white matter $[1,2]$. We describe a temporo-frontal hemorrhagic infarction demonstrated by computerized tomography scan (CT) in a child with CO exposure.

\section{Case presentation}

In the winter, a 7-year-old boy was admitted with history of persistent vomiting, progressive loss of consciousness and sever right hemiparesis. He had been well several hours before admission when he and all of his family members had developed vomiting, headache and lethargy.

Carbon monoxide poisoning was suspected based on a history of CO leakage from a gas stove at night subsequent to chimney obstruction, and similar symptoms in other co-habitants. All of them were admitted to hospital and subsequently had good recovery with standard treatment 
for CO poisoning. However, this young boy showed progressive worsening of symptoms including persistent vomiting, generalized convulsions, coma, and right hemiparesis.

Blood analysis revealed $\mathrm{pH}$ 7.4, $\mathrm{PCO}_{2} 35$ mmHg, $\mathrm{PO}_{2} 125$ $\mathrm{mmHg}$, a total hemoglobin concentration of $13 \mathrm{~g}$ with $75 \% \mathrm{HbO}_{2}, 24.5 \% \mathrm{HbCO}$ and $0.5 \%$ metHb.

Brain CT was performed on the day after admission which showed thick clot in left medial temporal and parasellar areas, intravascular thrombus in the left middle cerebral artery (Fig 1), diffuse left fronto-temporal hypodensity, and midline shift. Inspite of well known history of CO poisoning and brain CT suggestive of extensive hemorrhagic infarction, DSA angiography was done to exclude gross cerebral abnormalities but it was normal (Fig 2). A good recovery was found except for a global aphasia. Follow-up brain CT scan one year later revealed brain atrophy in left fronto-temporal area, which appeared to have been an evidence of resolving in a large hemorrhagic infarct (Fig 3).

\section{Discussion}

Carbon monoxide poisoning can produce three different forms of symptoms: acute intoxication, recurrent symptom syndrome and delayed neurocognitive or neuropsychiatric squeal. The clinical manifestations are influenced by both the duration of exposure and the concentration of $\mathrm{CO}$ in the environment. The toxic effects result predomi-

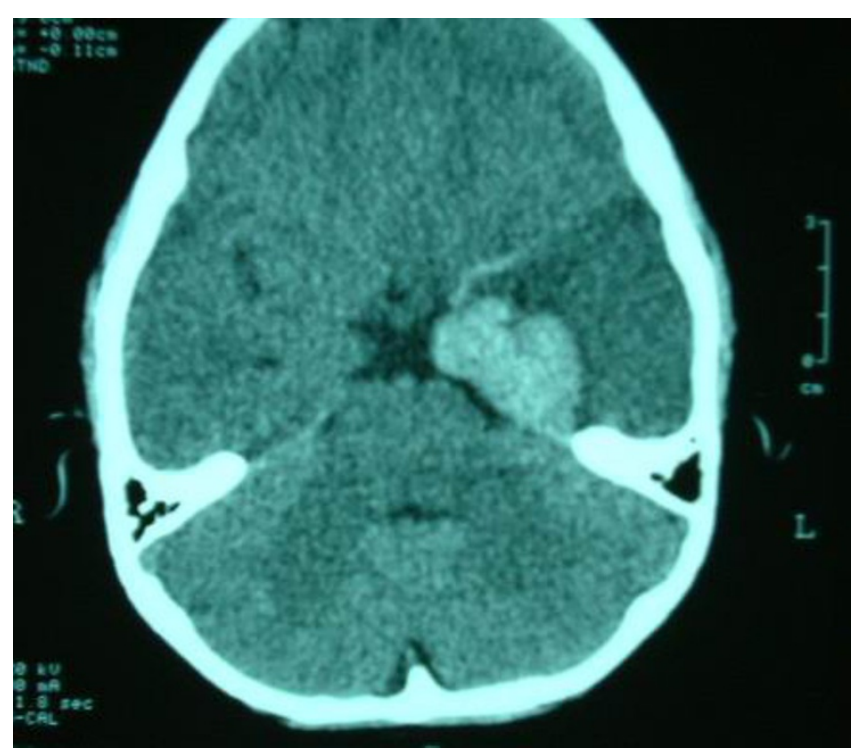

\section{Figure I}

Brain CT scan of the patient demonstrates thick clot in the left medial temporal and clot in left middle cerebral artery accompanied by left temporal hypodensity.

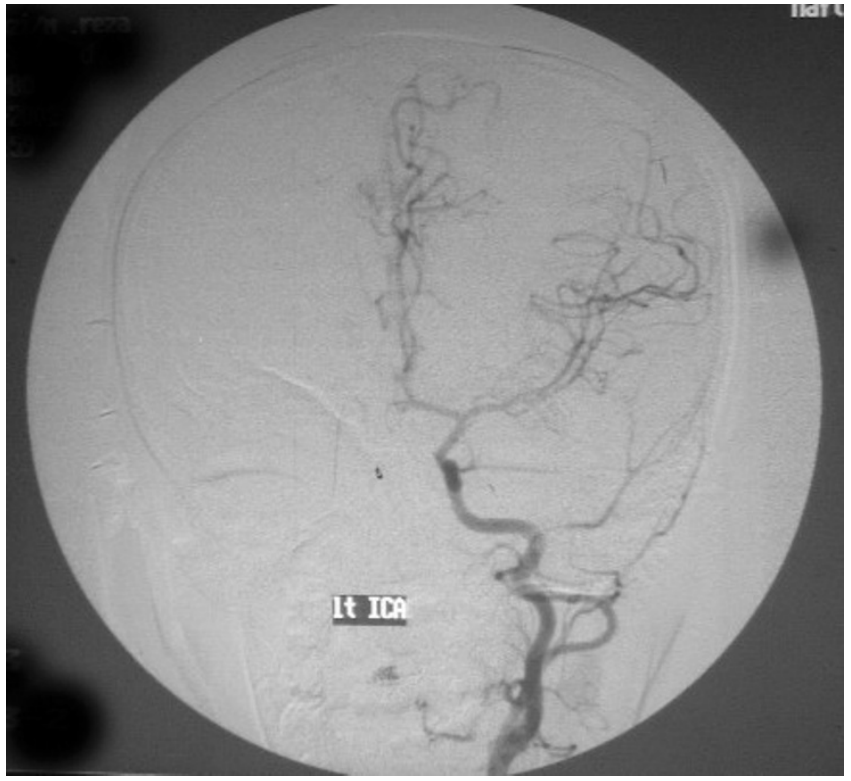

Figure 2

Left carotid angiogram shows normal anatomy of left carotid and middle cerebral arteries.

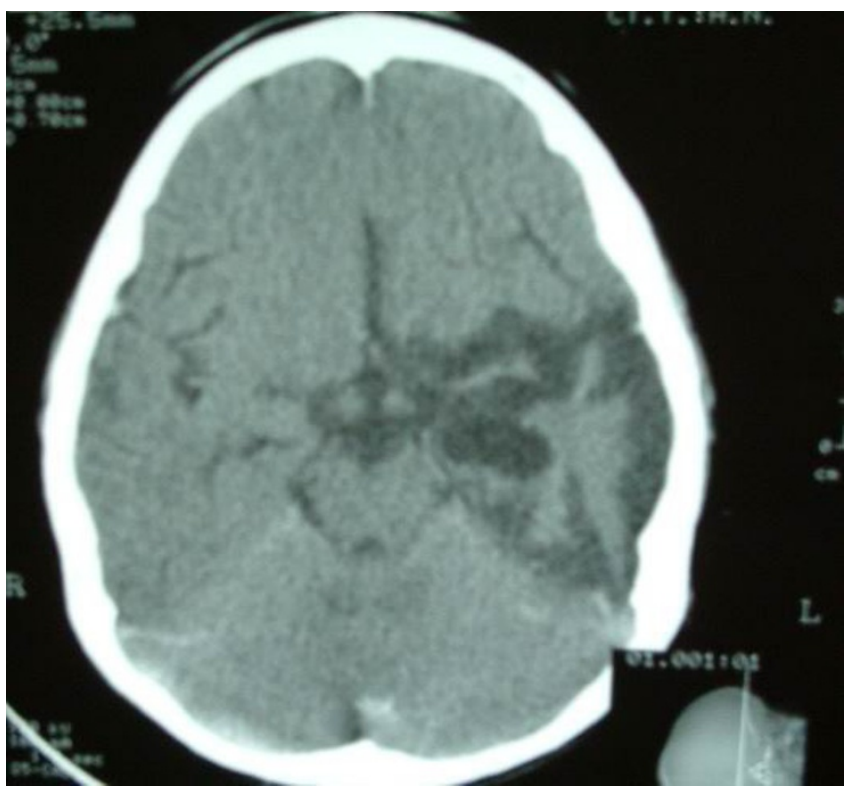

Figure 3

A, B: Follow-up CT scan demonstrates severe brain atrophy in previous hypodense area which confirms infracted brain was resolved. 
nantly from the interaction of $\mathrm{CO}$ with hemoglobin and also with other hem proteins such as myoglobin, cytochrome oxidase, cytochrome P-450, catalases and peroxidases. From anatomical perspective, the most common lesions occur in the basal ganglia and cerebral gray and white matters [1]. Cerebellar white matter damage has been explained. There is also loss of neurons in the cerebral and cerebellar cortices and so in the basal ganglia [1,2]. Pathologically, white matter changes range from small multifocal necrotic areas in the commissural and cerebral centrum to extensive zones of necrosis throughout both hemispheres. Symmetric subcortical demyelination is common and may account for delayed neurological deterioration. Cerebral edema can also be seen in severe poisoning and may lead to brain damage and focal neurological signs [3]. Focal hemorrhage in basal ganglia of patients with CO poisoning has been reported in autopsy and MRI findings [4]. Hemorrhagic infarct has rarely been considered as an early manifestation of CO poisoning $[3,4]$. The superiority of MRI over CT scan in detecting the presence of extravasated blood and establishing the diagnosis of hemorrhagic brain infarction has been well documented [5]. Brain CT scan is unable to detect petechial hemorrhage in patients with $\mathrm{CO}$ poisoning and can only show low-density areas of edema around the petechial hemorrhage [4].

Hemorrhagic infarction in the brain of patients referred for CO poisoning is very rare. We have tried to describe the probable mechanisms. Micro-vascular impairment and brain reperfusion injury patterns have been reported in CO poisoning and appear to be derived from uncontrolled oxidative damage initiated by oxygen free radicals, and sustained by second-generation lipid radicals. In addition, endothelial homeostasic disturbance due to local hypoxic injury from co-mediated mitochondria dysfunction has been documented in CO poisoning. Attraction of polymorph nuclear leukocytes to the site of oxidative endothelial injury perpetuates further free radical mediated injury. This micro vascular injury can produce ischemia and hemorrhage. Besides cardiovascular and hematological complications due to $\mathrm{CO}$ poisoning have been proposed to be another cause for hemorrhage.

According to history, initial similar symptoms in all of the family members (without pervious history supporting the present symptoms), and the laboratory test, it is logical to consider the case as a complication of $\mathrm{CO}$ poisoning. Brain CT revealed temporal lobe hemorrhage and intravascular thrombus inside left middle cerebral artery. The patient likely had hemorrhagic infarction. Although the hemorrhage was predominantly intracerebral. Digital subtraction angiography was done which couldn't find visible great vessel damage or incidental vascular abnormalities.

\section{Conclusion}

Hemorrhagic infarction is a rare presentation of carbon monoxide poisoning. When found in a child, in addition to conservative treatment to reduce the neurocognitive squeal, other probable causes should be ruled out.

\section{Consent}

Written informed consent was obtained from the patient's parents for publication of this case report. A copy of the written consent is available for review by the Editor-inChief of this journal.

\section{Competing interests}

The authors declare that they have no competing interests.

\section{Authors' contributions}

Both authors made contribution to conception, analyzed the patient data, and drafting the manuscript.

\section{References}

I. Bianco F, Floris R: MRI appearances consistent with hemorrhagic infarction as an early manifestation of carbon monoxide poisoning. Neuroradiology 1996, 38(SuppI I):S70-2.

2. Mascalchi M, Petruzzi P: MRI of cerebellar white matter damage due to carbon monoxide poisoning: case report. Neuroradiology 1996, 38:S73-74.

3. Schils F, Cabay JE, Flandroy P, Dondelinger RF: Unusual CT and MRI appearance of carbon monoxide poisoning. JBR-BTR I999, 82(I): I 3-5.

4. Sawada Y, Sakamoyo T, Nishide K, Sadamitsu D: Correlation of pathological findings with $C T$ finding after acute COP. NEJ Med 1983, 308: 1296.

5. Silverman CS, Brenner J, Murtagh FR: Hemorrhagic necrosis and vascular injury in carbon monoxide poisoning: MR demonstration. AJNR Am J Neuroradiol 1993, I4(1): 168-70.

Publish with Biomed Central and every scientist can read your work free of charge

"BioMed Central will be the most significant development for disseminating the results of biomedical research in our lifetime. " Sir Paul Nurse, Cancer Research UK

Your research papers will be:

- available free of charge to the entire biomedical community

- peer reviewed and published immediately upon acceptance

- cited in PubMed and archived on PubMed Central

- yours - you keep the copyright

Submit your manuscript here:

http://www.biomedcentral.com/info/publishing_adv.asp
BioMedcentral 